Esta obra está bajo una Licencia Creative Commons Atribución-NoComercial-Compartirlgual 4.0 Internacional

(c) (1) (8) ()

Testimonio, experiencia política y feminismo: Ana María Giacosa

Fabiana Hebe Grasselli y Mario Federico David Cabrera

DOI: https://doi.org/10.24215/16696581e202

Recibido: 30-06-2019 Aceptado: 15-11-2019

\title{
Testimonio, experiencia política y feminismo: Ana María - Giacosa
}

\section{Testimony, political experiencie and feminism: Ana María Giacosa}

Fabiana Hebe Grasselli sergio.piraino@gmail.com https://orcid.org/0000-0003-4416-4683

Instituto de Ciencias Humanas, Sociales y Ambientales; Consejo Nacional de Investigaciones Científicas y Técnicas/ Universidad Nacional de Cuyo (Argentina)

Mario Federico David Cabrera federicodavidcabrera@gmail.com https://orcid.org/0000-0002-0821-9977

Universidad Nacional de San Juan/ Consejo Nacional de Investigaciones Científicas y Técnicas (Argentina) 
Fabiana Hebe Grasselli y Mario Federico David Cabrera Testimonio, experiencia política y feminismo: Ana María Giacosa

\section{Resumen}

En este artículo nos proponemos analizar la narrativa testimonial de Ana María Giacosa (Jujuy 1940 - 1990) atendiendo especialmente a las relaciones entre escritura, género y experiencia política. Con este objetivo, focalizamos nuestro trabajo en un conjunto de relatos publicados a principios de los 80 en el libro Viaje alrededor de mi misma (1982) en los que la autora no solo se propone dar cuenta de su experiencia como militante peronista y presa política sino que además hace explícita la dimensión ética de la escritura en tanto espacio de disputa de memorias colectivas. En este sentido, sostenemos que sus textos desafían y desestabilizan con su existencia el mandato de silencio de la estructura represiva al tiempo que articulan un gesto antipatriarcal tematizando la dimensión sexuada de la experiencia narrada.

Palabras clave: Ana María Giacosa; testimonio; experiencia política; feminismo; corporalidad sexuada.

\section{Abstract}

In this article we propose to analyze the testimonial narrative of Ana María Giacosa (Jujuy 1940-1990) attending particularly the relationships between writing, gender and political experience. With this objective, we focus our work on a set of stories published in the early 80's in the book Viaje alrededor de mi misma (1982) where the author does not just aim to tell about her experience as a militant and political prisoner but also to explain the ethical dimension of writing as a space for the dispute of collective memories. In this sense, we argue that her texts challenge and destabilize with their own existence the mandate of silence of the repressive structure while articulating an anti-patriarchal gesture thematizing the sexuated dimension of the narrated experience.

Keywords: Ana María Giacosa; testimony; political experiencia; feminism; sexuated corporality.

Este trabajo se propone como una lectura inscripta en el cruce entre estudios culturales y estudios feministas sobre la narrativa testimonial de Ana María Giacosa a partir de la pregunta por los múltiples vínculos entre su experiencia como militante peronista y presa política, por un 
lado, y la práctica de la escritura testimonial, por otro. Con este objetivo, focalizamos en los relatos "Atención" (1982a), "Adiós, Caperucita, Adiós" (1982b), "Cuando casi fui gobernadora" (1982c) y "Cárcel" (1982d) publicados en el libro Viaje alrededor de mi misma por cuanto no solo tematizan explícitamente la actuación política de la escritora sino quedan cuenta también de tensiones referidas a la dimensión sexuada de la militancia y a las condiciones sociales de enunciación.

Ana María Giacosa, historiadora, escritora y periodista, figura importante dentro del escenario político de Salta durante los años setenta y ochenta, destacada militante de la Izquierda Nacional y reconocida luchadora por los derechos de las mujeres, publica el texto que nos ocupa en 1982, hacia el final de la última dictadura cívico- militar argentina (1976-1983). Habiendo atravesado las vivencias de la cárcel y el exilio interno, su narrativa se presenta como una compaginación de artículos, notas y relatos hilvanados desde un ejercicio de escritura política y autobiográfica que irrumpe en el archivo impuesto por el autoritarismo para aportar a una memoria colectiva contestataria que busca recuperar experiencias de resistencia de mujeres (1). Conviene recordar que, en este contexto, las mujeres que habían participado de organizaciones políticas y/o feministas se mantuvieron en espacios "de catacumbas" (Giberti, 1987), tejiendo lazos con el movimiento de derechos humanos, cultivando formas de resistencia cultural a la opresión imperante en una "modalidad autogestionada de soporte intelectual" (Bellucci, 2000) que se abocó al pensamiento político, social, artístico y filosófico.

Atendiendo a lo señalado, la metodología de trabajo busca interrogar un discurso testimonial sobre experiencias políticas de mujeres a partir de la hipótesis de que las formas de recordar/olvidar/narrar/nombrar la experiencia se hallan profundamente imbricados con las condiciones históricas y sociales de enunciación del recuerdo. En otras palabras, las posibilidades de realización de un testimonio y su plasmación en el lenguaje se vinculan con tramas colectivas de acciones y discursos que pugnan por rechazar los mandatos de silencio emanados de los sectores dominantes. De acuerdo con esto, en primer lugar, exponemos una serie de herramientas teórico- metodológicas para pensar las relaciones entre discurso social, experiencia política de mujeres y escritura testimonial. Luego, analizamos los procesos de autoconstrucción discursiva de la figura de la autora y los significados asociados a la corporalidad femenina en los textos del corpus. Por último, apuntamos algunas notas finales referidas a las modulaciones de la escritura testimonial en relación con las experiencias políticas de mujeres durante los años setenta. 
Fabiana Hebe Grasselli y Mario Federico David Cabrera Testimonio, experiencia política y feminismo: Ana María Giacosa

\section{Escritura, testimonio y experiencia política de mujeres}

Como hemos señalado, en este trabajo apelamos a una interrogación conjunta acerca de la relación entre experiencia política, discursividad social y el análisis de relatos testimoniales de mujeres. Para ello asumimos un enfoque que pone en diálogo los aportes de las teorías feministas y los desarrollos metodológicos provenientes del análisis social del discurso (Angenot, 2010; Maingueneau, 2002).

El elemento organizador de este itinerario interpretativo es la idea de enunciabilidad que gravita en la relación archivo/testimonio. Esto implica considerar la enunciación de un discurso en relación con sus condiciones históricas y sus posibilidades de realización. El testimonio funda su razón de ser en que desprende de "la huella vivida", y ese vestigio es la declaración de la existencia de lo acontecido (Ricoeur, 2003). Al respecto Alejandro Kaufman señala, desde una perspectiva benjaminiana, que reconstruir/recordar los hechos del pasado consiste en experimentar su significado a través de configuraciones narrativas de un "pasado presente" que se manifiesta como "relación con un aquí y ahora en deuda con el pasado, pero sin satisfacciones referenciales" (Kaufman, 2010: 3). La dialéctica entre historia y memoria atraviesa esta polémica evidenciando tensiones irreductibles y habilitando la posibilidad de abordar los procesos de historización del recuerdo. De este modo el énfasis es puesto en las condiciones históricas en las que las experiencias son recordadas, re-significadas y narradas, lo cual permite pensar al testimonio, a las narrativas testimoniales, no como "evidencia" histórica incontrastable, sino como lugar desde el cual pensar el mundo de lo social, es decir, un conocimiento situado: una noción de experiencia que, lejos de sentenciar la reificación ideológica del sujeto y sus condiciones de existencia (Scott, 1999), recupere su propia historicidad al señalar las tensiones que al interior de ella permiten re-escribir, re-narrar dichas experiencias a partir de los conflictos y disputas de su experiencia presente (Stone-Mediatore, 1999).

Como señala Giorgio Agamben, la potencia semántica y performativa de un enunciado testimonial radica en el hecho mismo de que tenga lugar (2000: 144). Esta afirmación habilita a considerar los discursos testimoniales como una praxis social que se inscribe en el terreno de la historia. Asimismo, esto presupone que la emergencia de estos discursos porta la evidencia no sólo de una irrupción en el archivo (lo habilitado socialmente para ser dicho, recordado, nombrado, narrado), sino también de un momento de ensanchamiento de los márgenes de aceptabilidad de lo que puede ser relatado y escuchado. El concepto de Angenot (2010) de discursividad social, entendida como los límites de lo pensable, lo decible y lo argumentable en una instancia específica de la historia, aporta especificaciones teórico-metodológicas que 
permiten comprender la apertura u oclusión de la enunciabilidad y la audibilidad de ciertos discursos. Desde este enfoque, las posibilidades de lo narrable se configuran en un movimiento dialéctico a partir del cual son habilitadas por procesos sociales y políticos, por encuentros de trayectorias marcadas por esos procesos, por entramados de solidaridades entre sujetos/as. Al mismo tiempo, el acontecer mismo del testimonio, su tener lugar, impacta sobre ese devenir histórico, colectivo y subjetivo.

Por otra parte, Adriene Rich (1986) y Audre Lorde (2007) explican la relación entre vivencias y narrativas de mujeres sobre una noción de experiencia elaborada desde una perspectiva epistemológica que considera la sexuación de lo vivido como clave de interpretación privilegiada. Desde esta perspectiva, articular esta mirada incluyente de la corporalidad de los/las sujetos/as, proporciona a la pesquisa un horizonte de reflexión según el cual el lenguaje, en tanto repertorio de discursos disponibles y legitimados en una sociedad y época determinadas, porta las huellas de la dominación patriarcal tendiendo a la neutralización y borramiento de las diferencias (Violi, 1991). Esto permite visibilizar las significaciones de las tensiones, silencios, contradicciones que están presentes en los discursos de mujeres, específicamente sus relatos y testimonios sobre experiencias políticas. Además permite atender a esa dimensión paradojal de esta palabra mujeril, en la cual lo que se narra, atravesado por la encarnadura de un cuerpo sexuado, aparece dicho en los bordes de lo decible y audible, a contrapelo de lo institucionalizado, e impregnado de ecos y murmullos de discursos de otras mujeres silenciados, no escuchados, no dichos todavía.

$\mathrm{Si}$, como plantea Dorothy Smith (1989), la experiencia sólo surge como diálogo entre lo vivido y la necesidad de evocarlo/relatarlo-para uno/a mismo/a o para algún/a interlocutor/a, el testimonio posibilita la emergencia de un lenguaje para hablar de lo previamente innominable e inaugura un proceso creativo a través del cual se puede llegar a traducir la experiencia en conciencia política (Stone-Mediatore, 1999). En el caso específico de la escritura testimonial de mujeres, es importante destacar que las enunciadoras dan cuenta de lo silenciado y, en este acto, delimitan un espacio político de enunciación que subvierte las lógicas de la "tutela" patriarcal (Colanzi, 2018: 100).

Desde este encuadre teórico- metodológico consideramos que los textos de Giacosa constituyen una intervención singular en los últimos años de la Dictadura pues ejecutan una coreografía de sentidos en la que se pone de relieve las tensiones entre lo silenciado y lo por decir. 
Fabiana Hebe Grasselli y Mario Federico David Cabrera Testimonio, experiencia política y feminismo: Ana María Giacosa

\section{Enfrentar el mandato de callar}

La Dictadura obturó las posibilidades de organización, debate y disenso. El terrorismo de Estado puso en marcha un plan sistemático de exterminio y persecución y convirtió en situaciones cotidianas la barbarie de los secuestros, desapariciones, cárceles y exilios. Ese proceso dejó marcas en las subjetividades y el tejido social que han sido elaboradas y reelaboradas colectivamente a lo largo de las últimas décadas (Feierstein, 2012: 17). En ese marco, como señala Alejandra Ciriza, la voluntad disciplinadora hacia las mujeres y disidentes sexuales se manifestó por medio de:

la aplicación de formas específicas de tortura, los ataques a la integridad sexual y las violaciones sistemáticas en los centros de detención clandestina, y también una tentativa de disciplinar las familias y la sexualidad bajo la égida de una moral conservadora y misógina que apelaba a la maternidad institucionalizada (Ciriza, 2017: 6).

Como señalamos al comienzo, para muchas mujeres militantes que escaparon de la desaparición forzada, la cárcel o el exilio, los grupos de estudio y pensamiento político, las organizaciones de derechos humanos y de mujeres significaron espacios de refugio (Ciriza, 2017: 6). Se trata de la etapa de cultura de "catacumbas", de repliegue en la reflexión y el debate teórico.

Los devenires feministas de muchas de esas mujeres tuvieron lugar en este escenario de principios de los años ochenta, sobre todo en el período en que comienzan a fortalecerse las voces de resistencia y el movimiento de derechos humanos cobra visibilidad. El fin de la Dictadura supuso para buena parte de las feministas transitar "[...] una lucha librada en muchos frentes, con objetivos urgentes como cambiar las leyes represivas [...] y obtener mínimos derechos democráticos como el divorcio vincular y la patria potestad compartida" (Tarducci, 2012: 7). Un buen número de organizaciones feministas surgieron en esta época: ATEM (Asociación de Trabajo y Estudios de la Mujer-25 de noviembre) en 1982, Lugar de Mujer, espacio emblemático para las feministas creado en 1983 e Indeso-Mujer (Instituto de estudios jurídicos sociales de la Mujer) nacido en Rosario en 1984 (Tarducci, 2012: 10). Asimismo, el conjunto de reivindicaciones sostenidas en torno a la equidad jurídica, el contrato sexual y las desigualdades de género se filtraron en las batallas ideológico-culturales y comenzaron, de modo incipiente, a ganar algún espacio en medios de comunicación gráficos. Hacia el final de la Guerra de Malvinas (1982) comenzaron a aparecer en diarios y revistas, de manera más o menos explícita, las preocupaciones del movimiento feminista (Tarducci, 2012: 
12). La figura pionera de María Moreno, quien dirigió el suplemento "La mujer" del diario Tiempo Argentino entre 1982 y 1986 y la revista feminista Alfonsina entre 1983 y 1984, da cuenta de la presencia de espacios intersticiales de la cultura que disputaban sentidos patriarcales en una especie de diálogo con el movimiento de mujeres (De Leone, 2011; Diz, 2011; Tarducci, 2012).

Por su parte, la trayectoria política y escritural de Ana María Giacosa (1940-1990) evidencia las huellas de ese clima de época y su impronta en los recorridos singulares y colectivos de las feministas de su generación. Nació en Jujuy, en el Ingenio Ledesma, fue dirigente política en diversas organizaciones de la Izquierda Nacional y dos veces candidata a gobernadora de Salta. Durante la dictadura fue encarcelada y sufrió el exilio interno. En esos años se organizó junto con otras compañeras sobrevivientes en AMUS, la Asociación de Mujeres de Salta, la primera organización feminista de la provincia, y más tarde, en 1983 fundó el Sindicato de Amas de Casa de la República Argentina. Fallecida en 1990, fue destacada por la Legislatura porteña en 2004 como una de las 18 personalidades femeninas del siglo XX, compartiendo el homenaje con figuras como Eva Perón, Alicia Moreau de Justo, María Luisa Bemberg y Azucena Villaflor, entre otras. Su texto testimonial, Viaje alrededor de mí misma, publicado en 1982, entrelaza dos operaciones escriturales que se configuran como una respuesta propia de su tiempo: el deber de testimoniar contra la imposición de silencio de la represión dictatorial y la necesidad de contribuir a la "memoria colectiva de un sexo" (Giacosa, 1982a: 7) nombrando la especificidad que la experiencia de lo político, la violencia y la resistencia tiene en la encarnadura de una subjetividad sexuada.

\section{Una mujer que (se) narra}

Maurice Hallbwachs (1950) nos ha enseñado que todo proceso de rememoración presupone la existencia de marcos sociales dinámicos que habilitan la puesta en discurso de las experiencias traumáticas. Dichos marcos tienen un carácter histórico e ideológicamente determinado por cuanto la construcción de las memorias colectivas se caracteriza por la convivencia de contradicciones, tensiones, silencios, conflictos, hiatos y disyunciones, así como instancias de "integración" (Jelin y Kaufman, 2006). Por otra parte, la producción del discurso testimonial escenifica la complejidad que supone el dar cuenta de sí (Butler, 2005) y la inscripción de las experiencias individuales en el espacio de lo colectivo (Bacci y Oberti, 2014). Atendiendo a estas formulaciones, en este apartado analizamos los textos de Giacosa a partir de dos preguntas: ¿De qué manera el punto de vista feminista y las historias de mujeres contribuyen a elaborar una crítica de la cultura y la política patriarcal? ¿Cuáles son las 
estrategias a través de las que se construye la voz de la narradora- testigo en relación con la experiencia de la violencia política?

Como ya señalamos, Viaje alrededor de mi misma reúne una serie de textos que constituyen intervenciones singulares inscriptas dentro de una genealogía que anuda herramientas del testimonio con el periodismo feminista (2). En esta doble genealogía, la escritura emerge como un dispositivo complejo de ruptura con formaciones culturales hegemónicas. Los quiebres que produce irrumpen frente a las "obediencias debidas" de la sexualidad y de la historia contada por la voz del patriarcado y de las instituciones del Estado represor.

Algunos artículos trabajan sobre distintos tópicos del periodismo feminista tales como introducir demandas propias del movimiento, denunciar el sexismo de los medios y tomar distancia respecto de la semiótica de las "revistas femeninas" (Diz, 2011). Además, Giacosa ensaya formas discursivas que se ubican en un espacio intersticial entre el cuadro de costumbres, la crónica y el testimonio. Así nos encontramos con textos que apuntan a desarticular las representaciones femeninas que circulan a través de las letras de tango, de los dichos populares e incluso en algunos medios de comunicación. En este sentido, la crítica feminista se revela como una crítica a las economías de sentido en torno a la producción de lo femenino (Richard, 2009). Citamos a modo de ejemplo un fragmento de "Indira Gandhi" referido al lugar de las mujeres en la política internacional:

Su poder no deviene de la herencia y de otros imponderables. Estas representantes están legitimadas por la voluntad colectiva para conducir el destino de sus pueblos. Esa es la diferencia. No han sido aceptadas, han sido elegidas de una u otra forma. No tienen la amable tarea de inaugurar los bailes de beneficencia ni de inaugurar las temporadas hípicas. No son como las reinas de los cuentos de hadas dispuestas a entregar el corazón y el trono al caballero que arroje más lejos el venablo. Tienen la dura responsabilidad de decidir sobre la paz, la guerra y el destino de sus pueblos (Giacosa, 1982e: 68).

Así, la crítica feminista en los textos de la autora funda un ejercicio semiótico y epistemológico a través del cual recorre su propia trama biográfica y social para señalar el complejo anudamiento entre lo personal y lo político, lo individual y lo colectivo, lo subalterno y lo hegemónico. En relación con esto, apenas abrimos el libro nos encontramos con unas palabras iniciales bajo el título de "Atención" a través de las cuales comenta de manera general el proceso de gestación de los textos y elabora una escena de enunciación en la que se anuda un punto de vista sexuado y una tarea hermenéutica que lucha contra el olvido y silencio:

Entrego muchas cosas en este libro, además de palabras y sueños.

Question, Vol. 1, N. ${ }^{\circ}$ 64, octubre-diciembre 2019. ISSN 1669-6581

Instituto de Investigaciones en Comunicación | Facultad de Periodismo y Comunicación Social | Universidad Nacional de La Plata La Plata | Buenos Aires | Argentina

Página 8 de 19 
La mujer es aquí la protagonista principal. No es fácil decidirse a otorgar trascendencia a las experiencias femeninas más comunes; a la visión particular de ciertos acontecimientos, épocas y personajes. La mirada femenina, la memoria colectiva de un sexo, ha permanecido generalmente oculta o discriminada de lo universal. La calificación de "diferente" siempre tuvo un sentido peyorativo [...] En ellas las cumbres serían siempre un poco menos altas y los abismos un poco más profundos. Las Medeas y las Antígonas fueron escasas porque los hombres eran los patroncitos de la literatura. No puede culpárselos de todo pero bajaron una pesada losa que todavía nos cuesta levantar para escribir con soltura- bien o mal- desde otra óptica, que aunque sutil, es diferente.

No encontré mucha ayuda en la literatura para aquello que quería decir. Fue un duro aprendizaje. Emprendí un viaje alrededor de mi misma, de la periferia al centro y al revés para encontrarme con "lo otro"... Mis reflexiones, críticas o novelescas, tal vez no tienen el alcance de una verdadera creación literaria. Tampoco lo pretendo. La realidad ha sido mi musa inspiradora y no toda desnudez es una obra de arte. A veces ni siquiera justifica una obra. Quisiera, en realidad, que muchas mujeres se vean de algún modo en estas páginas. Que encuentren escrito lo que han pensado o sentido alguna vez. En cuanto a los hombres que lleguen a leer este volumen quizás descubran facetas ignoradas de ese rostro familiar que los acompaña desde el nacimiento ¿Es una ambición fuera de medida? (Giacosa, 1982a: 7-8).

La práctica de la escritura se perfila, así, como un desacato frente a la institucionalidad de la literatura y el monolingüismo de la cultura patriarcal. Por fuera del arte y de la lengua, la figura de la narradora se presenta ante el destinatario como la hermeneuta que busca hilvanar retazos de memorias singulares, re narrar anécdotas y entrelazar la trama biográfica con interrogaciones políticas y sociales.

En este sentido, es interesante atender al ejercicio ensayístico que se realiza en el texto "Adiós, caperucita, adiós" (1982b). El relato conjura los recuerdos en torno a los modos de significar la historia de Caperucita Roja poniendo en diálogo dos momentos de la vida de la autora: cuando era una niña de cinco años y siendo la madre de una niña de cinco años. Se recrean desde un presente de mujer emancipada los sentires en tensión provocados por esa historia disciplinadora de la subjetividad mujeril: el miedo, la estupefacción frente al destino presentado como inevitable, la indignación frente al cercenamiento de las posibilidades para la aventura, la ingenuidad atribuida a las mujeres, la salvación siempre tutelada y proveniente de los varones, la felicidad sólo concebida en el proyecto del matrimonio. La narración de esos recuerdos es un volver a narrar el cuento en clave propia y mujeril, un volver a narrarse desde un presente en el que se impugna el control social sobre aquello que es el horizonte de lo posible para las mujeres. La operación consiste en una recuperación/un señalamiento de Caperucita Roja. El 
personaje es deconstruido como representación de las mujeres desde un estereotipo limitante, atrofiante, alienante. Pero, no obstante, al mismo tiempo que se denuncia el contenido patriarcal de dicha representación, se configura una reapropiación de Caperucita en un sentido de sororidad: las caperucitas que hemos sido empujadas a ser las mujeres son la consecuencia de relaciones de desigualdad (Cabrera, Grasselli y Fischetti, 2019).

Pero te juzgué, Caperucita, duramente y a tu madre también. ¿Cómo podías confundir a tu abuelita con un lobo? Eso determinó que nunca me sobrecogiera el in crescendo que terminaba en "Para comerte mejor". ¡Y tu madre que te mandaba sola por un bosque lleno de peligros con la orden de no detenerte ante las mariposas y las flores! Una niña de cinco años privada de cruzar la calle sola te siguió por el bosque y tu cerraste la puerta a la aventura terminando en la panza del lobo (1982c: 181).

En los relatos "Cuando casi fui gobernadora" (1982c) y "Cárcel" (1982d) la narradora pone en discurso su experiencia como militante y como presa política en el marco de las lógicas culturales e ideológicas de las décadas del 70 y del 80.Resulta interesante, en consecuencia, preguntarse acerca de los modos "producción de si" (Maingueneau, 2002) que pone en juego la instancia narradora a través de la intersección entre la experiencia individual y las condiciones sociales de enunciación (3).

"Cuando casi fui gobernadora" (1982c) asume un título que quiebra el orden sintáctico utilizado por la autora en otras piezas textuales del libro (o citas en estilo directo o construcciones sustantivas de artículo, núcleo y modificador directo) a través de una proposición adverbial en la que resuena el tono de la anécdota. Pero, sin embargo, el relato se encarga de detallar un acontecimiento de gran trascendencia dentro de la trayectoria política de la narradora: la campaña electoral que la llevó a constituirse en la primera candidata a gobernadora de la historia del país. Esta tensión entre un tono que parece desmarcarse de esquemas retóricos y un relato de acontecimientos de gran densidad política atraviesa el texto como una de las principales herramientas de autoconstrucción. Así,la narradora se presenta como un cuerpo político atravesado por múltiples tensiones entre una femineidad asociada a debilidad y pasividad y el signo masculino que hegemoniza las presentaciones públicas en la disputa electoral; entre los privilegios de clase y posición y la militancia y lo colectivo; entre los honores y el trabajo de base. Citamos, a modo de ejemplo, los siguientes fragmentos:

La proclamación no tuvo ribetes cinematográficos y no tuve tiempo de dormitar un poco sobre mis laureles. Tampoco fantaseé sobre la probable notoriedad- afortunadamente, ya que fue nula- devenida de la circunstancia de ser la primera mujer candidata a gobernadora 
en la historia del país. La campaña de afiliación que significó abrir el camino a nuestras banderas sin más recursos que la voluntad y el poder de persuasión, había sido gratificante pero durísima (1982c: 79).

Yo que nací en el Trópico y aprendí a gatear sobre la familiar piel de tigre, era vergonzosamente derrotada por aquellos 48 grados a la sombra. Debí aceptar un lugar en la mesa y la cerveza helada que me ofrecían el amigo Isa y los miembros del partido de Manrique. Mis compañeros me miraban con desaprobación. Había resultado una candidata debilucha, venal y una social demócrata podrida. Seguramente por eso nadie me tendió una mano para ayudarme a subir al palco. Trepé por los travesaños en un revuelo de polleras y agradezco que la ayuda de mis convidadores llegara tarde (1982c: 87).

Por otra parte, hacia el final del relato la narradora introduce un conjunto de reflexiones sobre la situación del país en el contexto de la Dictadura para repensar la experiencia del proyecto político al que pertenece. Estas reflexiones se organizan en torno a la disputa por las significaciones asociadas a la idea de "patria": entre la retórica de "un ellos"- generalizable a los sectores de la sociedad civil asociados al poder terrorista de la Dictadura- y la idea del patriotismo como práctica empática:

La patria ya no sería jamás un concepto abstracto o una imagen literaria. Por primera vez la vimos desnuda. Contrahecha, maravillosa y dispar... Engolados personajes hablarían de "política con mayúscula" mientras abogaban por un país minúsculo. Según ellos, cosas como las que cuento no deberían repetirse. Constituyeron una experiencia nefasta que debe ahorrarse a los jóvenes de hoy. Tocar el rostro de la pobreza o contemplar la libre carrera de una corzuela puede despertar pensamientos peligrosos para un país probeta (1982c: 99-100).

En "Cárcel" (1982d), por su parte, la narradora se aboca al relato de su experiencia como presa política entre marzo y abril de 1976. En un escenario en el que el Golpe de Estado se presenta como la única certeza, la militante de 36 años es advertida del peligro que corre pero, sin embargo, decide enfrentar sus responsabilidades como apoderada de su partido político. Es interesante, en este sentido, la manera en que la narradora se identifica a sí misma como participante de una genealogía de presos y presas políticos en la historia de nuestro país: "Para los políticos la cárcel siempre es una posibilidad. La prisión por causas políticas era una figura familiar para mí [...] Crecí en la convicción que los presos políticos eran una institución nacional en la Argentina" (1982d: 102-103). 
La narradora, en esta primera parte, caracteriza su accionar a través de la calma, la confianza en las instituciones y cierta despreocupación pero, no obstante, el ritmo narrativo se interrumpe en el momento en que le cubren los ojos con una venda. En ese momento, "todas las historias ajenas de secuestros, fusilamientos y torturas eran mías" (1982d: 106) nos dice. Al igual que en el relato anterior, el cuerpo se presenta como un territorio en el que se disputan las tensiones socio-políticas (4). Para la narradora se hace indispensable mostrar un cuerpo resistente como una extensión de una voluntad política inquebrantable:

\begin{abstract}
Observaba mi cuerpo todos los días. Estaba bastante presentable. Si me hacían desnudarcomo decían- ofrecería un aspecto digno. Sin rollos indiscretos ni músculos vencidos. No sería más humillante que ir al baño con la puerta abierta. No podría depilarme las axilas, pero después de todo no iba a posar para un pintor. Parece cómico pero creo que pensaba en algo parecido. Quería mostrarme firme por dentro y por fuera. Tal vez era el único desafío permitido. Hasta había previsto cómo reaccionar ante el agua fría. Estaba resuelta a no presentar una imagen encogida y lamentable (1982d: 113).
\end{abstract}

La corporalidad se configura en esa subjetividad enunciativa como un oxímoron encarnado de lo propio y lo ajeno. El cuerpo adquiere protagonismo como arma de resistencia propia y, al mismo tiempo, como herida en el que el opresor inocula el terror. En esa ambivalencia, en esa tensión, se articula la narración de una experiencia sexuada, contestataria, que impugna al silencio y demanda una ética de escucha.

Lo que insiste: narrar contra el silencio

Agamben (2000) sostiene que la noción de testimonio es una potencia que adquiere realidad mediante una impotencia de decir: una imposibilidad que cobra existencia por medio de la posibilidad de hablar. Por ello mismo "el testimonio", al contrario del archivo que concibe al sujeto como "simple función" o como "posibilidad vacía", instaura la relación entre la posibilidad de decir y su tener lugar, entre la posibilidad de decir y la imposibilidad de decir, como contingencia, como un poder no ser.El concepto de archivo corresponde básicamente al sistema general de la formación y de la transformación de los enunciados que configuran un campo de saber. Es aquello que puede ser dicho. El valor político y ético del testimonio radica justamente en que relata una vivencia destinada a no ser dicha y que, sin embargo, es narrada. Entre el relato singular y el archivo se establece una relación tal que abre o cierra la posibilidad de que los/las sujetos/as hablen, de la misma manera que modela las formas de narración de las experiencias políticas y las maneras de (re)significarlas. Así, las formas de Question, Vol. 1, N. ${ }^{\circ} 64$, octubre-diciembre 2019. ISSN 1669-6581

Instituto de Investigaciones en Comunicación | Facultad de Periodismo y Comunicación Social | Universidad Nacional de La Plata 
recordar/olvidar/narrar/nombrar la experiencia de la sexuación dependen de las condiciones histórico-sociales.

Recuperamos esta conceptualización del testimonio como una ganzúa para abrir una estrategia de indagación sobre las tramas ideológicas de las narrativas de Giacosa. En otras palabras, desde esta política de lectura que se configura atendiendo al registro testimonial de los relatos "Cuando casi fui gobernadora" y "Cárcel", hemos buscado identificar cómo condensan las significaciones que gravitan en torno a la escritura de la experiencia. Así, es posible advertir en ambos relatos el ideologema (5) del decir contra el silencio.

En "Cuando casi fui gobernadora" hacia el final del texto la narradora hace una afirmación que resignifica el racimo de anécdotas señalando las búsquedas performativas de su relato: "Según ellos, cosas como las que cuento no deberían repetirse. Constituyeron una experiencia nefasta que debe ahorrarse a los jóvenes de hoy" (1982c: 100). Este enunciado se organiza como una operación de explicitación del carácter testimonial de lo narrado en función de la cual las vivencias relatadas exigen una re-lectura. No se trata de una biografía inofensiva sobre experiencias políticas de una mujer, sino que constituye la narración de lo que no debe ser dicho. Se trata de un texto que desafía con su existencia y su insistencia el mandato de silencio de los poderosos. Dar lugar a la narración de una experiencia política con horizontes emancipatorios, dejar huellas en el discurso acerca de que esa experiencia fue transitada por una subjetividad encarnada en un cuerpo de mujer, constituye una praxis política contestataria. En ese gesto, es decir, en el gesto de la palabra escrita, se sostiene su contenido disruptivo, rebelde y peligroso, el cual está dado por el hecho mismo de la escritura y la narración de las experiencias acalladas.

Una operación similar aparece en "Cárcel". El cierre del texto alude a la intención de la narradora de contar lo vivido durante su detención como presa política. La narración testimonial se articula aquí no sólo como un "relato de los hechos" surgido del deber y voluntad políticos de testimoniar, sino también como una necesidad subjetiva que reconoce en la palabra una posibilidad para transitar el daño sufrido. El silencio es lo rechazado, la narración de la historia de vida es lo que permite seguir habitando las relaciones y un mundo que se ha reconfigurado luego de la derrota social, económica, política y cultural que significó la Dictadura:

Ya en casa me permití llorar y aturdir a todos los amigos con mi historia [...] Pocos días después envié una carta a una amiga que la conservó y me la dio cuando le dije que pensaba escribir sobre el tema: Como era de suponer idealicé la libertad soñando que me bañaba en arroyos cristalinos, que deglutía platos deliciosos y que protagonizaba escenas 
Fabiana Hebe Grasselli y Mario Federico David Cabrera Testimonio, experiencia política y feminismo: Ana María Giacosa

eróticas propias del Idilio-Film. Ahora me enfrento con la libertad a la que tengo acceso (destacado en el original) (1982d: 118).

El relato de la narradora no sólo insiste en ser pronunciado sino que en numerosas ocasiones exhibe la encarnadura sexuada de la enunciación. En "Cuando casi fui gobernadora" se tematiza el ejercicio del discurso político en clave mujeril dando cuenta, principalmente, de las consecuencias políticas de las relaciones patriarcales. La realidad de la exclusión y falta de legitimación de la palabra de las mujeres en la arena de lo público es presentada como denuncia y desafío. A través de la anécdota de su participación en un programa de televisión en calidad de figura política, el discurso político es denunciado como "propiedad de los varones" y el ejercicio de la palabra por parte de una mujer se reivindica como una "expropiación", es decir, un acto de reparación:

Tomé del cenicero el cigarrillo del candidato de la Nueva Fuerza que estaba a mi lado [...] Quizá fuera un acto de expropiación inconsciente. Otros manifestaron haber sufrido por mí; sola entre una mayoría de propietarios, cercada por la hostilidad corporizada en las frecuentes interrupciones y las escasas preguntas (1982c: 94).

Como ya señalamos, en el relato "Cárcel" la narración de las vivencias tiene la marca de la corporalidad. Las experiencias de miedo, hambre, dolor, soledad, decepción, resistencia son relatadas poniendo en el centro de la escena el cuerpo. En varios pasajes la alusión a ese cuerpo tiene la huella de la sexuación. El rencor adquiere la forma del cansancio, la desesperanza se traduce en un sueño profundo, el terror es un rayo helado que atraviesa desde el cerebro a la garganta, la humillación es el llanto de una niña. La densidad simbólica que adquiere el solapamiento de la evocación de la infancia y el llanto de una mujer construye una imagen de suma vulnerabilidad y desamparo, como si un destino de amenaza e intemperie fueran la síntesis de la niñez de las mujeres, como si esa intemperie remitiera a una corporalidad acechada siempre por la violencia:

A pesar de que no tenía necesidad urgente, pedí que me llevaran al baño. Me condujeron a empujones, tropezando bajo la lluvia, dos policías femeninas pero no feministas [...] La tensión contenida cedió y la humillación pudo más que el miedo a la muerte y lloré como en la infancia todo el camino de vuelta (1982d: 109).

En otro pasaje, la sensación de persecución es relatada como una pesadilla en la que se huye de una violación inminente. La autora sueña que está con poca ropa junto a otras compañeras, 
quienes advierten sobre la llegada de un vehículo atiborrado de varones borrachos. Las mujeres corren aterradas porque saben que ellos "no respetarían ni pelo ni marca" (1982d: 115). La cárcel y la represión se metamorfosean en la pesadilla convirtiéndose en amenaza de violación colectiva conjurando una superposición entre violencia genocida y violencia patriarcal. Así, es posible afirmar que la discursividad mujeril de Giacosa dice rechazando la imposición del silencio y bregando por la inscripción en el orden de lo político de las vivencias marcadas por las consecuencias políticas de la diferencia sexual.

\section{Palabras finales}

La escritura de Ana María Giacosa se presenta como una praxis que entrelaza la responsabilidad ética de denunciar la violencia de la Dictadura y la necesidad de disputar un espacio de representación para las experiencias políticas de mujeres. El diálogo entre organizaciones feministas y el movimiento de derechos humanos, el fortalecimiento de modos de encuentro y organización entre mujeres, la apertura de espacios para la práctica escritural en clave feminista constituyen el escenario que habilita la posibilidad para la producción de un texto como Viaje alrededor de mí misma. La trayectoria político-intelectual de Ana María Giacosa, que es subjetiva pero se desenvuelve en los andares colectivos de las feministas de su generación, se abre paso como parte de un proceso social y cultural en el cual la recuperación de los jirones de una memoria subversiva no renuncia a articular junto a las experiencias políticas de las mujeres una historia de la resistencia de los sectores populares.

Siguiendo esa clave hemos indagado tanto en las estrategias textuales de autoconstrucción discursiva de la figura de la autora como en las significaciones que se configuran en los relatos sobre la corporalidad mujeril, habida cuenta de que este tipo de testimonios interviene en los trabajos de la memoria colectiva en pugna con las historias oficiales, pero también desde un lugar de desobediencia a los mandatos patriarcales. Emerge en este escrito, entonces, una narrativa testimonial de resistencia, política y poética, cuyo gesto primordial es pronunciar lo silenciado, hacer audible lo inaudito. En ese gesto el relato ensaya modos de decir que aspiran a visibilizar las tensiones simbólicas, sociales y políticas presentes en las palabras y los cuerpos mujeriles cuando relatan sus experiencias de militancia. Las modulaciones de estos decires habitan la complejidad de repudiar la desigualdad de género a la vez que reivindican ese oxímoron referido a la rebeldía y vulnerabilidad de las mujeres viviendo a contracorriente de los mandatos sociales.

Si como dice Pilar Calveiro el testimonio en tanto "práctica resistente" es una actualización de experiencias que parte del rescate de "escombros", de "lo roto (y lo derrotado), es decir, el 
'resto' recuperable para rearticularlo con las urgencias actuales" (Calveiro, 2014: s/p), el texto de Giacosa aparece como una voz, que a tono con las luchas feministas de los primeros años ochenta, intenta inscribir en el terreno de una tradición política contestataria un "nosotras" desnaturalizador de las experiencias de militancia neutralizadas, invisibilizadas, marginalizadas. Se trata de un relato que dialoga con las reivindicaciones de las organizaciones de mujeres de la época así como con los trazos pioneros del periodismo feminista a tiempo que contribuye a un flujo de memorias subalternas que no se han dejado domesticar. Son las memorias cuya tarea de nombrar la experiencia sexuada se presenta como una práctica narrativa que articula una tradición de palabras sobre nosotras y para nosotras, al tiempo que construye genealogías de luchadoras.

Notas

(1) Es importante destacar que, pese a la relevancia de Ana María Giacosa en el campo político de las décadas del 70 y del 80 , son prácticamente inexistentes las referencias a su trayectoria literaria y política en estudios críticos con excepción del libro de Hernández (2017) y el artículo de Cabrera, Grasselli y Fischetti (2019).

(2) Tania Diz (2011) rastrea una genealogía de periodismo feminista en Argentina que se remonta hasta el siglo XIX con publicaciones como La aljaba, La camelia, Álbum de señoritas, La voz de la mujer, La nota y Alfonsina. Por su parte, Grasselli (2015) señala la existencia de una serie de producciones testimoniales publicadas durante los años setenta que evidencian la tensa y compleja relación entre experiencias políticas de mujeres, la voluntad de transformación social nominada "revolución" y las posibilidades habilitadas en esa particular coyuntura para poner en palabras esas experiencias. En esta serie se destacan: La patria fusilada de Francisco Urondo, La guerrilla tupamara de María Esther Giglio y Carta a mis amigos de Rodolfo Walsh.

(3) Entendemos la noción de "producción de si" -en relación con el "ethos discursivo"- como una herramienta retórica que permite articular una voz con una posición social para dar cuenta de las negociaciones y efectos de sentido que se ejecutan en la construcción de la propia imagen del enunciador (Maingueneau, 2002).

(4) Patricia Rotger (2015) afirma que en la violencia sistemática desplegada sobre los cuerpos de los detenidos- desaparecidos en la última Dictadura Cívico- Militar ha operado como un principio de feminización y "quiebre" como extensión metafórica del avasallamiento de las subjetividades e identidades políticas. 
(5) "Llamaremos ideologema a toda máxima, subyacente a un enunciado, cuyo sujeto lógico circunscribe un campo de pertinencia particular [...] Esos sujetos, desprovistos de realidad sustancial, no son más que seres ideológicos determinados y definidos únicamente por el conjunto de máximas isotópicas en que el sistema ideológico les permite ubicarse" (Angenot, 2007: 8).

\section{Bibliografía}

Agamben, G. (2000). Lo que queda de Auschwitz. El archivo y el testigo. Homo sacer III. Valencia, España: Pre-textos.

Angenot, M. (2007). Presupuesto/topos/ideologemas (Trad. Laura Varela). En La parole pamphlétaire. Contribution à la typologie des discours modernes (1-14). Paris, Francia: Payot.

Angenot, M. (2010). El discurso social. Los límites de lo pensable y lo decible. Buenos Aires, Argentina: Siglo XXI.

Bacci, C. y Oberti, A. (2014). Sobre el testimonio. Una introducción. Clepsidra. Revista Interdisciplinaria de Estudios sobre Memoria, 1(1), 6-13.

Bellucci, M. (2000). El feminismo de los años perdidos. Río Negro. Recuperado de https://bit.ly/38ITVAM

Butler, J. (2005). Giving on account of oneself. Nueva York, EEUU: Forham UP.

Cabrera, M.; Grasselli, F. y Fischetti, N. (2019). Vida que se escribe/escritura que se vive. Boletin GEC, 23, 32-52. Recuperado de http://revistas.uncu.edu.ar/ojs/index.php/boletingec/article/view/1778

Calveiro, P. (2014). Sentidos políticos del testimonio en tiempos del miedo. Milán, s/p.

Ciriza, A. (2017). Militancia y academia: una genealogía fronteriza. Estudios feministas, de género y mujeres en Mendoza. Descentrada. Revista interdisciplinaria de feminismos y género, $1(1), \quad 1-21 . \quad$ Recuperado de http://www.memoria.fahce.unlp.edu.ar/art_revistas/pr.7717/pr.7717.pdf

De Leone, L. (2011). Una poética del nombre: los "comienzos" de María Moreno hacia mediados de los años 80 en el contexto cultural argentino. Cuadernos Pagu, 36, 223256.

Diz, T. (2011). Tensiones, genealogías y feminismos en los 80. Un acercamiento a Alfonsina, primer periódico para mujeres. Mora, 17(2), s/p.

Feierstein, D. (2012). Memorias y representaciones. Sobre la elaboración del genocidio. Buenos Aires, Argentina: Fondo de Cultura Económica. 
Giacosa, A. M. (1982a). Atención. En Viaje alrededor de mi misma (pp. 7-10). Buenos Aires, Argentina: Editorial del Mar Dulce.

Giacosa, A. M. (1982b). Adiós, Caperucita adiós. Viaje alrededor de mi misma (pp. 180-182). Buenos Aires, Argentina: Editorial del Mar Dulce.

Giacosa, A. M. (1982c). Cuando casi fui gobernadora. En Viaje alrededor de mi misma (pp. 79101). Buenos Aires, Argentina: Editorial del Mar Dulce.

Giacosa, A. M. (1982d). Cárcel. En Viaje alrededor de mi misma (pp. 102-119). Buenos Aires, Argentina: Editorial del Mar Dulce.

Giacosa, A.M. (1982e). Indira Gandhi. En Viaje alrededor de mi misma (pp. 66-72). Buenos Aires, Argentina: Editorial del Mar Dulce.

Giberti, E. (1987). Prólogo. En Burin M. y otras. Estudios sobre la subjetividad femenina, Mujeres y salud mental. Buenos Aires, Argentina: GEL.

Grasselli, F. (2015). Experiencias políticas de mujeres, relatos de militancia y escritura testimonial durante los años 70. Textos de Rodolfo Walsh, Francisco Urondo y María Esther Giglio desde una lectura en clave de género. La aljaba. Segunda época, XIX, 183-200.

Hallbwachs, M. (1950). Le mémoire collective. Paris, Francia: Puf.

Hernández, P. (2017). El despertar de las muchachas. Buenos Aires, Argentina: Fabro.

Jelin, E. y Kaufman, S. (2006). Los niveles de la memoria: reconstrucción del pasado dictatorial argentino. Revista Entrepasados, 20/21, 9-34.

Kaufman, A. (2010). Aduanas de la Memoria: A propósito de Tiempo Pasado de Beatriz Sarlo. Recuperado de http://rayandolosconfines.com/critica_kaufman.html

Lorde, A. (1984). La hermana, la extranjera. Madrid, España: LIFS.

Maingueneau, D. (2002). Problèmesd'ethos. Practiques, 113-114, pp. 55-67.

Ricoeur, P. (2003) La memoria, la historia, el olvido. Madrid: Editorial Trotta.

Rich, A. (1996). Nacemos de mujer. La maternidad como experiencia e institución. Valencia, España: Cátedra.

Richard, N. (2009). La crítica feminista como modelo de crítica cultural. Debate feminista, 40, 75-85.

Rotger, P. (2015). Memoria sin tiempo. Prácticas narrativas de la memoria en escritoras argentinas de la posdictadura. Córdoba, Argentina: Comunicarte.

Scott, J. W. (2001). Experiencia. La ventana, 13, pp. 42-73.

Smith, D. (1989). El mundo silenciado de las mujeres. Santiago, Chile: CIDE.

Stone-Mediatore, S. (1999). Chandra Mohanty y la revalorización de la experiencia. Revista Hiparquia, 10(1), 85-109.

Question, Vol. 1, N. ${ }^{\circ}$ 64, octubre-diciembre 2019. ISSN 1669-6581

Instituto de Investigaciones en Comunicación | Facultad de Periodismo y Comunicación Social | Universidad Nacional de La Plata 
Fabiana Hebe Grasselli y Mario Federico David Cabrera Testimonio, experiencia política y feminismo: Ana María Giacosa

Tarducci, M. (2012). El feminismo de los primeros años de la democracia. Brujas. Publicación feminista, 38, 7-16.

Violi, P. (1991). El Infinito Singular. Madrid, España: Cátedra. 